\title{
Cardiometabolic risk and the MTHFR C677T variant in children treated with second-generation antipsychotics
}

\author{
AM Devlin, YF Ngai, R Ronsley and C Panagiotopoulos
}

\begin{abstract}
Second-generation antipsychotics (SGAs) are increasingly being used to treat children with a variety of psychiatric illnesses. Metabolic syndrome (MetS), a risk factor for cardiovascular disease, is a side-effect of SGA-treatment. We conducted a crosssectional study and assessed the association of the methylenetetrahydrofolate reductase (MTHFR) C677T variant with features of MetS in SGA-treated $(n=105)$ and SGA-naïve $(n=112)$ children. We targeted the MTHFR C677T variant, because it is associated with risk for cardiovascular disease, and features of MetS in adults without psychiatric illness. MetS in children is based on the presence of any three of the following: waist circumference $\geqslant 90$ th percentile for age and sex; plasma triglyceride $\geqslant 1.24 \mathrm{mmolI}^{-1}$; plasma high-density lipoprotein-cholesterol $\leqslant 1.03 \mathrm{mmolI}^{-1}$; systolic or diastolic blood pressure $\geqslant 90$ th percentile for age, sex, and height; and fasting glucose $\geqslant 5.6 \mathrm{mmol} \mathrm{I}^{-1}$. We found that $15 \%$ of SGA-treated children had MetS compared with $2 \%$ of SGA-naïve children (OR 8.113, $P<0.05$ ). No effect of the MTHFR C677T variant on psychiatric diagnosis was observed. The MTHFR $677 \mathrm{~T}$ allele was associated $(P<0.05)$ with MetS $(\mathrm{OR} 5.75,95 \% \mathrm{Cl}=1.18-28.12)$ in SGA-treated children. Models adjusted for duration of SGA treatment, ethnicity, sex, age and use of other medications revealed a positive relationship between the MTHFR 677 T allele and diastolic blood pressure $Z$-scores $(P=0.001)$ and fasting plasma glucose $(P<0.05)$ in SGA-treated children. These findings illustrate the high prevalence of MetS in SGA-treated children and suggest metabolic alterations associated with the MTHFR C677T variant may have a role in the development of MetS features in SGAtreated children.
\end{abstract}

Translational Psychiatry (2012) 2, e71; doi:10.1038/tp.2011.68; published online 24 January 2012

\section{Introduction}

Metabolic syndrome (MetS) is a side-effect associated with use of second-generation antipsychotic (SGA) medications in adults. ${ }^{1}$ SGAs, also known as atypical antipsychotics, are increasingly being used to treat children with a wide range of psychiatric illnesses, including anxiety disorder, attention deficit hyperactivity disorder, bipolar disorder, depressive disorder, pervasive developmental disorder, psychotic disorder and disruptive behavior disorder. Recent estimates have shown that SGA prescriptions for children (14 years and younger) in British Columbia increased 10-fold from 19972007. ${ }^{2}$ Concern is now being raised as to whether MetS develops in children treated with SGAs and the potential longterm consequence of this side-effect.

One classification of MetS in children is based on the National Cholesterol Education Program-Adult Treatment Panel definition ${ }^{3}$ and modified to adhere to the American Diabetes Association definition of impaired fasting glucose of $\geqslant 5.6 \mathrm{mmoll}^{-1}$. ${ }^{4}$ This definition includes the presence of any three of the following features: waist circumference $\geqslant 90$ th percentile for age and sex; plasma triglyceride (TG) $\geqslant 1.24 \mathrm{mmoll}^{-1}$; plasma high-density lipoprotein (HDL) $\leqslant 1.03 \mathrm{mmoll}^{-1}$; systolic or diastolic blood pressure $\geqslant 90$ th percentile for age, sex, and height; and fasting glucose $\geqslant 5.6 \mathrm{mmoll}^{-1}$. We recently conducted a cross-sectional study and found that $19 \%$ of SGA-treated children $(n=84)$ had MetS compared with $0.8 \%$ of SGA-naïve children ( $n=127)(P<0.001) .^{5}$ Furthermore, a prospective study showed that SGA-naïve children initiated on SGA treatment and followed for a mean duration of 10.8 weeks had significant increases in weight, body mass index (BMI), waist circumference, and plasma TGs relative to untreated children. ${ }^{6}$ This study further showed that the effect of SGA treatment on other cardiometabolic risk factors was SGA-specific with elevated fasting blood glucose levels observed only in children treated with olanzapine. The means by which to distinguish children at risk for developing MetS from those that do not and the mechanism by which MetS develops in SGA-treated children are not known.

Methylenetetrahydrofolate reductase (encoded by MTHFR), is an enzyme that coverts folate, a B-vitamin, to the metabolically active form of 5-methyltetrahydrofolate. Homozygosity for a common variant in MTHFR, C677T, occurs in $\sim 10 \%$ of individuals of European descent ${ }^{7}$ and is associated with increased risk of schizophrenia, ${ }^{8}$ major

Department of Pediatrics, University of British Columbia, Child and Family Research Institute, Vancouver, Canada

Correspondence: Dr AM Devlin, Department of Pediatrics, University of British Columbia, Child and Family Research Institute, 272-950 West 28th Ave, Vancouver V6K 4A9, Canada or Dr C Panagiotopoulos, Department of Pediatrics, University of British Columbia, Endocrinology and Diabetes Unit, British Columbia Children's Hospital, 4480 Oak St, ACB K4-213, Vancouver, V6H 3V4, Canada.

E-mail: adevlin@cfri.ubc.ca or dpanagiotopoulos@cw.bc.ca

Keywords: blood pressure; children; impaired fasting glucose; metabolic syndrome; MTHFR; second-generation antipsychotics

Received 8 November 2011; revised 9 December 2011; accepted 11 December 2011 
depressive disorder and bipolar disorder in adults. ${ }^{8,9}$ Interestingly, homozygosity for this variant is also associated with increased risk of coronary heart disease, ${ }^{10}$ and a recent cross-sectional study found that $53 \%$ of SGA-treated adult schizophrenia patients that carried the T-allele had MetS compared with $23 \%$ of SGA-treated adult schizophrenia patients with the CC genotype. ${ }^{11}$

As a first step towards delineating the mechanism by which MetS develops in SGA-treated children, we assessed the association of the MTHFR C677T variant with features of MetS in a cross-sectional population of SGA-treated and SGA-naïve children with mental illness. Furthermore, given the association of the MTHFR C677T variant with psychiatric illness in adults, ${ }^{8,9}$ we also assessed the association of the MTHFR C677T variant with psychiatric diagnoses in these children.

\section{Materials and methods}

Study design and patient recruitment. A cross-sectional study design was used to examine the relationship between the MTHFR C677T variant and the metabolic consequences of SGA-treatment in children. Study participants were inpatients of either the emergency or long-stay units of the Child and Adolescent Psychiatry Department at British Columbia Children's Hospital. Patients were assessed between April 2008 and June 2011. Inclusion criteria included: either currently receiving SGA-treatment (SGAtreated patients) or not currently being treated with an SGA on admission or not previously treated with an SGA (SGA-naïve patients), and $\leqslant 18$ years of age. Exclusion criteria included: known cardiometabolic or endocrine disease (including pre-existing type 1 and type 2 diabetes mellitus), diagnosed eating disorder or current treatment with medications known to affect metabolism (e.g., glucocorticoids). On admission, parents or legal guardians provided written informed consent to participate in the study. Children provided written assent where capable. All protocols described were approved by the University of British Columbia Clinical Research Ethics Board and the Children's and Women's Health Centre Research Ethics Board.

\footnotetext{
Clinical, biochemical and anthropometric measurements. The medical records of patients were reviewed over the course of admission and the following data were collected: sociodemographic information (sex, age, self-reported ethnicity); medical history, including psychiatric diagnoses, and medications (including dose and duration); smoking habits, family medical and psychiatric illness history. The Global Assessment of Functioning score (range: 1-100), designed to reflect overall psychological, social and occupational functioning, and not functioning based upon physical impairments, was determined by the attending psychiatrist using a Multiaxial evaluation as described in the DSM-IV-TR. ${ }^{12}$ Psychiatric diagnoses were based on independent assessments by two Royal College of Physicians and Surgeons (Canada)-certified psychiatrists.
}

Anthropometric measures included height, weight and waist circumference. Weight was assessed in patients wearing light clothing, pockets emptied, without shoes or socks, and recorded to the nearest $0.1 \mathrm{~kg}$ (Tronix Scale model 5002, White Plains, NY, USA). Height was assessed in patients to the nearest $0.1 \mathrm{~cm}$ (Seca 240 Stadiometer, Hamburg, Germany). Waist circumference was assessed using a non-elastic flexible tape measure at the level of the umbilicus (two measurements averaged). ${ }^{13} \mathrm{BMI}$ was calculated (weight $(\mathrm{kg}) /$ height $^{2}\left(\mathrm{~m}^{2}\right)$ ) and then standardized for sex and age using data from the US Centers for Disease Control growth charts. ${ }^{14}$ Overweight was defined as BMI $\geqslant 85$ th and $<95$ th percentile, and obesity as BMI $\geqslant 95$ th percentile for age and sex. ${ }^{15}$

Diastolic and systolic blood pressure measures (average of three readings) were collected after the child had settled into the unit (at least $24 \mathrm{~h}$ post admission), using a Dinamap automated monitor and an appropriately sized cuff. ${ }^{16} \mathrm{~A}$ blood sample was collected by venipuncture after an overnight fast of $\geqslant 8 \mathrm{~h}$. The following biochemical analyses were conducted in the clinical laboratory at British Columbia Children's Hospital: plasma glucose, insulin, total cholesterol, lowdensity lipoprotein cholesterol, HDL, TG, alanine aminotransferase and aspartate aminotransferase.

MetS was diagnosed based on the National Cholesterol Education Program-Adult Treatment Panel definition ${ }^{3}$ and modified to adhere to the American Diabetes Association definition of impaired fasting glucose. ${ }^{4}$ A diagnosis was made based on the presence of any three of the following features: waist circumference $\geqslant 90$ th percentile for age and sex; ${ }^{17}$ plasma $\mathrm{TG} \geqslant 1.24 \mathrm{mmoll}^{-1}$; plasma $\mathrm{HDL} \leqslant 1.03 \mathrm{mmoll}^{-1}$; systolic or diastolic blood pressure $\geqslant 90$ th percentile for age, sex, and height; ${ }^{16}$ and fasting plasma glucose $\geqslant 5.6 \mathrm{mmoll}^{-1}$.

Genomic DNA isolation and genotyping. Buccal epithelial cells were collected by scraping the inner cheek of patients with collection swabs (Puritan Medical Products, Guilford, ME, USA). Genomic DNA was isolated using the QIAamp DNA Mini Kit (Qiagen, Mississauga, Canada) and quantified using a NanoVue Spectrophotometer (GE Healthcare, Montreal, Canada). Genotyping of the MTHFR C677T variant (rs1801133) was accomplished using Taqman SNP Genotyping reagents and a 7500 Real-Time PCR System (Applied Biosystems, Foster City, CA, USA).

Statistical analyses. Subjects were categorized as SGAtreated and SGA-naïve. Pearson's $\chi^{2}$-tests were used to compare categorical variables between SGA-treated and SGA-naïve patients. General linear models were used to compare continuous variables between SGA-treated and SGA-naïve patients. Logistic and linear regression models were used to assess the effect of the MTHFR C677T genotype on MetS diagnosis and characteristics of MetS. Models were adjusted for age, sex, duration of SGA treatment, treatment with medications known to promote weight gain (mood stabilizers, antidepressants and firstgeneration antipsychotics), treatment with medications known to promote weight loss (psychostimulants and Atomoxetine) and ethnicity. Analyses were conducted using SPSS software version 18.0 (SPSS, Chicago, IL, USA). 


\section{Results}

Socio-demographic, anthropometric and metabolic characteristics of study population. In total, 261 subjects consented to the study; 44 subjects were excluded due to pre-existing cardiometabolic disease, endocrine abnormalities, diagnosed eating disorders and/or treatment

Table 1 Characteristics of the study population

\begin{tabular}{|c|c|c|c|}
\hline Characteristic & $\begin{array}{l}\text { SGA-treated } \\
(n=105)\end{array}$ & $\begin{array}{c}\text { SGA-naive } \\
(\mathrm{n}=112)\end{array}$ & $\mathrm{P}$ value \\
\hline $\begin{array}{l}\text { Age (years), mean (s.d.) } \\
\text { Male sex, } n(\%)\end{array}$ & $\begin{array}{r}12.58(3.14) \\
70(66.7)\end{array}$ & $\begin{array}{r}13.19(2.86) \\
64(57.1)\end{array}$ & $\begin{array}{l}0.133 \\
0.096\end{array}$ \\
\hline $\begin{array}{l}\text { Ethnicity, } n(\%) \\
\text { European } \\
\text { Asian } \\
\text { Aboriginal } \\
\text { South Asian } \\
\text { African/Caribbean } \\
\text { Hispanic } \\
\text { Other }\end{array}$ & $\begin{array}{c}77(74.0) \\
9(8.7) \\
3(2.9) \\
3(2.9) \\
7(10.7) \\
5(4.8) \\
0(0)\end{array}$ & $\begin{array}{c}79(70.5) \\
9(8.0) \\
4(3.6) \\
3(2.7) \\
12(10.6) \\
4(3.6) \\
1(0.9)\end{array}$ & 0.890 \\
\hline $\begin{array}{l}\text { Smoker, } n(\%) \\
\text { GAF score, mean (s.d.) } \\
\text { SGA median duration in } \\
\text { months (range) }\end{array}$ & $\begin{array}{c}15(15.0) \\
54.05(10.83) \\
6.00(0.25-76.0)\end{array}$ & $\begin{array}{c}21(19.1) \\
55.13(8.68) \\
\text { N/A }\end{array}$ & $\begin{array}{l}0.274 \\
0.436\end{array}$ \\
\hline $\begin{array}{l}S G A \\
\text { Quetiapine, n (\%) } \\
\text { Risperidone, n (\%) } \\
\text { Aripiprazole, n (\%) } \\
\text { Olanzapine,n (\%) } \\
\text { Ziprasidone, n (\%) }\end{array}$ & $\begin{array}{c}49(46.7) \\
46(43.8) \\
5(4.8) \\
4(3.8) \\
1(1.0)\end{array}$ & & \\
\hline
\end{tabular}

Abbreviations: GAF, global assessment of functioning; NA, not applicable; SGA, second-generation antipsychotic.

Differences between SGA-treated and SGA-naïve patients were assessed by unadjusted Pearson's $\chi^{2}$-tests for categorical variables and by general linear models for continuous variables. with glucocorticoids; and 8 subjects did not have DNA collected. The socio-demographic and characteristics of the subjects are given in Table 1. There were no differences in age, sex, ethnicity, smoking or global assessment of functioning scores between SGA-treated and SGA-naïve children. The majority of our study population was of European-descent (74\% SGA-treated and 71\% SGA-naïve). The median duration of SGA-treatment was 6 months (ranging from 0.25 to 76 months). The majority of SGAtreated children were receiving quetiapine $(46.7 \%)$ or risperidone (43.8\%) (Table 1$)$. Children were also often treated with other medications including antidepressants, psychostimulants, mood stabilizers, atomoxetine and first generation antipsychotics, which were controlled for in our logistic and linear regression models.

Similar to our previous findings, SGA-treated children had higher $(P<0.05)$ zBMI with $30.1 \%$ of SGA-treated patients having a $\mathrm{BMI} \geqslant 95$ th percentile compared with $17 \%$ of SGAnaïve patients (Table 2). SGA-treated children had a higher $(P=0.001)$ prevalence of MetS (15.6\% of patients) than SGAnaïve children (2.1\% of patients), with an odds ratio of 8.11 (95\% Cl=1.41-46.77) (Table 2). We further assessed characteristics of the MetS and found that SGA-treated children had higher $(P<0.05)$ systolic blood pressure $Z$-scores; a higher $(P<0.05)$ prevalence of children with blood pressure $\geqslant 90$ th percentile for age, sex and height; and a higher $(P<0.05)$ prevalence of children with waist circumference $\geqslant 90$ th percentile for age and sex than SGAnaïve children. SGA-treated children also had higher fasting plasma glucose $(P=0.005)$, insulin $(P<0.043)$, total cholesterol $(P<0.01)$ and low-density lipoprotein $(P<0.05)$ levels compared with the SGA-naïve patients (Table 2).

Table 2 Cardiometabolic characteristics of the study population

\begin{tabular}{|c|c|c|c|}
\hline Characteristic & SGA-treated $(n=105)$ & SGA-naive $(\mathrm{n}=112)$ & $\mathrm{P}$ value \\
\hline MetS, $n(\%)$ & $15(15.6)$ & $2(2.1)$ & 0.001 \\
\hline $\begin{array}{l}\text { zBMI, mean (s.d.) } \\
\text { aobese, } n(\%) \\
\text { overweight, } n(\%) \\
\text { normal, } n(\%)\end{array}$ & $\begin{array}{c}1.013(0.979) \\
31(30.1) \\
23(22.3) \\
49(47.6)\end{array}$ & $\begin{array}{l}0.731(0.973) \\
18(17.0) \\
24(22.6) \\
64(60.4)\end{array}$ & 0.038 \\
\hline $\begin{array}{l}\text { WC } \geqslant 90^{\text {th }} \text { percentile, } n(\%) \\
\text { WC }(\mathrm{cm}), \text { mean (s.d.) }\end{array}$ & $\begin{array}{r}39(37.1) \\
78.9(15.0)\end{array}$ & $\begin{array}{r}28(25.0) \\
77.3(17.5)\end{array}$ & $\begin{array}{l}0.037 \\
0.488\end{array}$ \\
\hline $\begin{array}{l}\text { BP } \geqslant 90 \text { th percentile, } n(\%) \\
\text { SBP Z-score, mean (s.d.) } \\
\text { DBP Z-score, mean (s.d.) }\end{array}$ & $\begin{array}{r}25(25.0) \\
0.445(1.07) \\
0.409(0.72)\end{array}$ & $\begin{array}{r}15(14.4) \\
0.112(0.90) \\
0.412(0.67)\end{array}$ & $\begin{array}{l}0.042 \\
0.016 \\
0.976\end{array}$ \\
\hline $\begin{array}{l}\text { Impaired fasting glucose }\left(\geqslant 5.6 \mathrm{mmoll}^{-1}\right), n(\%) \\
\text { Fasting glucose }\left(\mathrm{mmoll}^{-1}\right) \text {, mean (s.d.) } \\
\text { Fasting insulin }\left(\mathrm{pmoll}^{-1}\right) \text {, mean (s.d.) }\end{array}$ & $\begin{array}{c}6(5.7) \\
4.92(0.34) \\
61.31(40.76)\end{array}$ & $\begin{array}{c}3(2.7) \\
4.78(0.34) \\
50.94(26.02)\end{array}$ & $\begin{array}{l}0.218 \\
0.005 \\
0.043\end{array}$ \\
\hline $\begin{array}{l}\text { Elevated TG }\left(\geqslant 1.24 \mathrm{mmoll}^{-1}\right), n(\%) \\
\quad \mathrm{TG}\left(\mathrm{mmoll}^{-1}\right), \text { mean (s.d.) }\end{array}$ & $\begin{array}{r}24(22.9) \\
1.09(0.67)\end{array}$ & $\begin{array}{r}19(17.0) \\
0.96(0.41)\end{array}$ & $\begin{array}{l}0.179 \\
0.100\end{array}$ \\
\hline $\begin{array}{l}\text { Low HDL }\left(\leqslant 1.03 \mathrm{mmoll}^{-1}\right), n(\%) \\
\operatorname{HDL}\left(\mathrm{mmolI}^{-1}\right), \text { mean (s.d.) }\end{array}$ & $\begin{array}{r}23(21.9) \\
1.32(0.39)\end{array}$ & $\begin{array}{r}15(13.4) \\
1.30(0.30)\end{array}$ & $\begin{array}{l}0.071 \\
0.716\end{array}$ \\
\hline $\begin{array}{l}\text { LDL }(\text { mmol I } \\
\text { Total cholesterol }\left(\text { mmoll }^{-1}\right) \text {, mean (s.d.) } \\
\text { AST (U/L), mean (s.d.) } \\
\text { ALT (U/L), mean (s.d.) }\end{array}$ & $\begin{array}{c}2.76(0.96) \\
4.54(1.05) \\
32.57(12.24) \\
22.82(16.12)\end{array}$ & $\begin{array}{c}2.45(0.72) \\
4.19(0.84) \\
30.12(10.22) \\
20.74(13.66)\end{array}$ & $\begin{array}{l}0.017 \\
0.009 \\
0.138 \\
0.339\end{array}$ \\
\hline
\end{tabular}

Abbreviations: ALT, alanine aminotransferase; AST, aspartate aminotransferase; BMI, body mass index; BP, blood pressure; DBP, diastolic blood pressure; HDL, high-density lipoprotein cholesterol; LDL, low-density lipoprotein cholesterol; MetS, metabolic syndrome; SBP, systolic blood pressure; SGA, second-generation antipsychotic; TG, triglyceride; WC, waist circumference.

The effect of SGA-treatment was analyzed by unadjusted Pearson's $\chi^{2}$-tests for categorical variables and unadjusted general linear models for continuous variables. ${ }^{\mathrm{a}}$ Obese $=\mathrm{BMI} \geqslant 95^{\text {th }}$ percentile; overweight $=\mathrm{BMI} \geqslant 85$ th percentile; and normal $=\mathrm{BMI}<85^{\text {th }}$ percentile. 
Association of the MTHFR C677T variant with psychiatric diagnosis. The MTHFR 677TT genotype occurs at a frequency of $\sim 10-12 \%$ in populations of Europeandecent. ${ }^{7,18}$ In this study, we found 17 out of $209(8.1 \%)$ of our study patients (8 out of 99 SGA-treated and 9 out of 110 SGA-naïve) had the MTHFR $677 T$ T genotype with a $27 \%$ Tallele frequency. Given the association of the MTHFR C677T variant with psychiatric illness in adults, ${ }^{8,9}$ we assessed the association of the MTHFR C677T variant with psychiatric diagnoses in our pediatric study patients. The patients in our study had a wide-range of psychiatric diagnoses. As such, patients with multiple DSM-IV Axis I diagnoses were assessed under multiple diagnostic categories. Interestingly, we found no association between the MTHFR C677T variant and psychiatric diagnoses in our patient population (Table 3 ).

Association of the MTHFR C677T variant and MetS characteristics. A higher prevalence of MetS has been previously reported in SGA-treated adults with schizophrenia carrying the T-allele of the MTHFR C677T variant than those with the CC genotype. ${ }^{11}$ As such, we investigated the association of the MTHFR C677T variant with MetS and MetS components in the SGA-treated children in our study population. The SGA-naïve patients were not included in this analysis, because of the low prevalence of MetS diagnosis $(2 \%)$ in this group. We found that SGA-treated patients carrying the T-allele had a higher prevalence $(P<0.05)$ of MetS, higher $(P=0.005)$ diastolic blood pressure $Z$-scores, and higher $(P<0.05)$ fasting plasma glucose compared with patients with the CC genotype (Table 4). Further analyses using logistic regression models adjusted for duration of SGA-treatment, ethnicity, sex, age and use of other medications revealed that the $\mathrm{T}$ allele of the MTHFR C677T variant was associated with a greater $(P=0.03)$ chance of having MetS (odds ratio $=$ $5.75,95 \% \mathrm{Cl}=1.18-28.12)$.

Table 3 MTHFR C677T variant and pediatric psychiatric diagnoses

\begin{tabular}{|c|c|c|c|}
\hline \multirow[t]{2}{*}{ Diagnosis } & \multicolumn{3}{|c|}{ MTHFR C677T Genotype } \\
\hline & $C C(\mathrm{n}=113)$ & $C T$ and $T T(\mathrm{n}=96)$ & P value \\
\hline Psychotic disorder, $n(\%)$ & $11(9.7)$ & $8(8.3)$ & 0.812 \\
\hline Depressive disorder, $n(\%)$ & $29(25.7)$ & $22(22.9)$ & 0.448 \\
\hline Bipolar disorder, $n(\%)$ & $55(48.7)$ & $49(51.0)$ & 0.174 \\
\hline Anxiety disorder, $n(\%)$ & $14(12.4)$ & $16(16.7)$ & 0.884 \\
\hline $\mathrm{ADHD}, n(\%)$ & 36 (31.9) & $26(27.1)$ & 0.707 \\
\hline Disruptive behavior disorder, $n(\%)$ & $14(12.4)$ & $11(11.5)$ & 0.672 \\
\hline Pervasive developmental disorder, $n(\%)$ & $7(6.2)$ & $14(14.6)$ & 0.056 \\
\hline Substance-related disorder, $n(\%)$ & $11(9.7)$ & $9(9.4)$ & 0.930 \\
\hline
\end{tabular}

Abbreviations: ADHD, attention deficit hyperactivity disorder; MTHFR, methylenetetrahydrofolate reductase.

The effect of the MTHFR C677T variant on pediatric psychiatric diagnoses was analyzed by Pearson's $\chi^{2}$-tests.

Table 4 Cardiometabolic characteristics of SGA-treated patients and MTHFR C677T genotype

\begin{tabular}{|c|c|c|c|}
\hline \multirow[t]{2}{*}{ Characteristic } & \multicolumn{3}{|c|}{ MTHFR C677T genotype } \\
\hline & $C C(\mathrm{n}=54)$ & $C T$ and $T T(\mathrm{n}=45)$ & P value \\
\hline MetS, $n(\%)$ & $4(7.8)$ & $10(25.0)$ & 0.039 \\
\hline $\begin{array}{l}\text { WC } \geqslant 90^{\text {th }} \text { percentile, } n(\%) \\
\text { WC }(\mathrm{cm}), \text { mean (s.d.) } \\
\text { BMI } Z \text {-score, mean (s.d.) }\end{array}$ & $\begin{array}{c}16(29.6) \\
76.3(13.4) \\
0.897(0.885)\end{array}$ & $\begin{array}{c}20(44.4) \\
80.5(15.2) \\
1.111(1.084)\end{array}$ & $\begin{array}{l}0.146 \\
0.170 \\
0.285\end{array}$ \\
\hline $\begin{array}{l}\text { BP } \geqslant 90 \text { th percentile, } n(\%) \\
\text { SBP Z-score, mean (s.d.) } \\
\text { DBP Z-score, mean (s.d.) }\end{array}$ & $\begin{array}{l}\quad 9(17.3) \\
0.278(1.08) \\
0.195(0.755)\end{array}$ & $\begin{array}{l}13(31.0) \\
0.562(1.07) \\
0.604(0.596)\end{array}$ & $\begin{array}{l}0.145 \\
0.205 \\
0.005\end{array}$ \\
\hline $\begin{array}{l}\text { Fasting glucose } \geqslant 5.6 \mathrm{mmol} \text {, } n(\%) \\
\text { Fasting glucose }\left(\mathrm{mmoll}^{-1}\right) \text {, mean (s.d.) } \\
\left.\text { Fasting insulin (pmoll }{ }^{-1}\right) \text {, mean (s.d.) }\end{array}$ & $\begin{array}{c}2(3.7) \\
4.85(0.30) \\
56.27(37.96)\end{array}$ & $\begin{array}{c}3(6.7) \\
5.01(0.37) \\
65.00(43.06)\end{array}$ & $\begin{array}{l}0.657 \\
0.028 \\
0.318\end{array}$ \\
\hline $\begin{array}{l}\text { TG } \geqslant 1.24 \mathrm{mmoll}^{-1}, n(\%) \\
\text { TG }\left(\mathrm{mmoll}^{-1}\right), \text { mean (s.d.) } \\
\text { HDL } \leqslant 1.03 \mathrm{mmol} \mathrm{I}^{-1}, n(\%) \\
\text { HDL }\left(\mathrm{mmol} \mathrm{I}^{-1}\right) \text {, mean (s.d.) } \\
\left.\text { LDL (mmoll }{ }^{-1}\right) \text {, mean (s.d.) } \\
\left.\text { Total cholesterol (mmol }{ }^{-1}\right), \text { mean (s.d.) }\end{array}$ & $\begin{array}{r}10(18.5) \\
1.10(0.71) \\
12(22.2) \\
1.35(0.36) \\
2.71(0.92) \\
4.58(1.03)\end{array}$ & $\begin{array}{r}13(28.9) \\
1.09(0.57) \\
10(22.2) \\
1.27(0.42) \\
2.91(1.00) \\
4.62(1.06)\end{array}$ & $\begin{array}{l}0.242 \\
0.896 \\
1.000 \\
0.304 \\
0.331 \\
0.850\end{array}$ \\
\hline
\end{tabular}

Abbreviations: BMI, body mass index; BP, blood pressure; DBP, diastolic blood pressure; HDL, high-density lipoprotein cholesterol; LDL, low-density lipoprotein cholesterol; MetS, metabolic syndrome; MTHFR, methylenetetrahydrofolate reductase; SBP, systolic blood pressure; SGA, second-generation antipsychotic; TG, triglyceride; WC, waist circumference.

The effect of the MTHFR C677T variant on cardiometabolic characteristics was analyzed by unadjusted Pearson's $\chi^{2}$-tests for categorical variables and unadjusted general linear models for continuous variables. 
Table 5 Relationship between the MTHFR C677T variant and cardiometabolic characteristics in SGA-treated children

\begin{tabular}{lcc}
\hline Characteristic & Standardized $\boldsymbol{\beta}$-coefficient & P value \\
\hline BMI Z-score & 0.095 & 0.357 \\
WC & 0.150 & 0.090 \\
SBP Z-score & 0.172 & 0.068 \\
DBP Z-score & 0.313 & 0.001 \\
Fasting glucose & 0.256 & 0.022 \\
Fasting insulin & 0.120 & 0.259 \\
Triglyceride & 0.003 & 0.978 \\
HDL & -0.123 & 0.249 \\
\hline
\end{tabular}

Abbreviations: BMI, body mass index; DBP, diastolic blood pressure; HDL, high-density lipoprotein cholesterol; SBP, systolic blood pressure; SGA second-generation antipsychotic; WC, waist circumference.

Adjusted for duration of SGA treatment, ethnicity, sex, age and use of other medications.

Linear regression models adjusted for duration of SGAtreatment, ethnicity, sex, age and use of other medications were used to assess the relationship of the MTHFR C677T genotype with individual characteristics of MetS in SGAtreated children. The T-allele of the MTHFR C677T variant was positively associated with diastolic blood pressure $Z$ scores $(\beta$-coefficient $=0.313, P=0.001)$ and fasting glucose levels $(\beta$-coefficient $=0.256, P<0.05)$ (Table 5$)$. No relationships were observed between anthropometric measures (waist circumference, BMI Z-scores) and plasma HDL and TG levels (Table 5).

\section{Discussion}

The goal of this study was to determine if the MTHFR C677T variant is associated with psychiatric diagnoses and characteristics of the MetS in a cross-sectional population of SGAtreated children and SGA-naïve children recruited through our inpatient psychiatric units. There are three main findings of this study. As we predicted, we found that MetS is more prevalent in SGA-treated children compared with SGA-naïve children. Elevated blood pressure and elevated fasting glucose, both components of the MetS, are also more prevalent in SGA-treated children compared with SGA-naïve children. Interestingly, we found that the MTHFR C677T variant was associated with increased prevalence of MetS in SGA-treated children, with the T-allele associated with significantly higher blood pressure and higher fasting plasma glucose levels than children with the MTHFR $677 \mathrm{CC}$ genotype.

This current study confirms the higher prevalence of MetS in a second, distinct population of SGA-treated children and is similar to the findings of our initial study that showed MetS is more prevalent in SGA-treated children than in SGA-naïve children. ${ }^{5}$ Studies in adults have reported MetS in $37.3 \%$ of SGA-treated patients, ${ }^{1}$ which is higher than the prevalence rates of $15.6 \%$ in SGA-treated children (median duration 6 months) in the current study and $19 \%$ in SGA-treated children (median treatment duration of 14 months) in our prior study. ${ }^{5}$ The difference in prevalence rates between adults and children is likely because MetS is not as common in children as it is in adults.
When we further investigated differences in the components of the MetS between SGA-treated and SGA-naive children, we found higher waist circumference, blood pressure, and fasting plasma glucose levels but no differences in plasma TGs or HDL in the SGA-treated children compared with SGA-naïve children. A study in children treated with risperidone and followed for 8 weeks found significant increases in body weight, BMI Z-scores and waist circumference, but no differences in plasma lipids or glucose. ${ }^{19}$ Another study showed that children treated with olanzapine and risperidone and followed for 4 weeks had significant increases in BMI, but only those treated with olanzapine had elevations in blood pressure and diagnosis of MetS from baseline ${ }^{20}$ suggesting the type of SGA-treatment may influence the development of MetS characteristics. However, in our current study only $3.8 \%$ of the children were treated with olanzapine, with the majority treated with either risperidone $(43.8 \%)$ or quetiapine $(46.7 \%)$, similar to our prior study. ${ }^{5}$ Furthermore, a prospective study showed significant increases in BMI $Z$-scores, waist circumference, fat mass and TGs in children initiated on treatment with olanzapine, risperidone or quetiapine and followed for a mean duration of 10.8 weeks. ${ }^{6}$ However, only olanzapine treatment in this study was associated with significant elevations in fasting blood glucose. Taken together, these studies suggest that both the type of SGA treatment and duration of treatment may influence the development of MetS characteristics.

Surprisingly, we found no association of the MTHFR 677T allele with psychiatric diagnoses. Studies in adults have reported an association between the MTHFR 677TT genotype and bipolar disorder, major depressive disorder and schizophrenia.,9 Furthermore, we recently found greater depressed mood in pregnant women that were homozygous for the MTHFR C677T variant, an effect that was not influenced by serotonin reuptake inhibitor treatment. ${ }^{21}$ In the current study we did not assess the effects of the MTHFR $677 T T$ genotype on psychiatric diagnosis because of the low frequency of the genotype in our population. Further larger studies are required to definitely assess the effects of the MTHFR 677TT genotype on psychiatric diagnosis in children.

Similar to what has been reported in studies in SGA-treated adults with schizophrenia, ${ }^{11}$ we found a significant association of the T-allele of the MTHFR C677T variant with MetS and also observed a positive association of the T-allele with diastolic blood pressure Z-scores and fasting plasma glucose levels. However, others have reported no association of the MTHFR C677T variant with MetS in SGA-treated adults, but did report an association between the MTHFR A1298C variant and MetS. ${ }^{22}$ Further, this same group investigated the influence of the MTHFR C677T and A1298C variants on the development of MetS characteristics within the first 3 months of SGA-treatment and reported that only the MTHFR 1298CC genotype was associated with greater weight gain, fasting plasma glucose and plasma glucose concentrations at 120 min during an oral glucose tolerance test. ${ }^{23}$ However, another study reported no effect of the MTHFR A1298C variant on MetS in SGA-treated adults. ${ }^{11}$ We also assessed the effect of the MTHFR A1298C variant in our population, but found no association with MetS or its components. This may in part be because of the low frequency of the MTHFR 
1298CC genotype (7.1\%) in our patients (unpublished data).

Little is known regarding the mechanisms by which the MTHFR C677T variant may be associated with MetS in SGAtreated children. The MTHFR enzyme is required for the metabolism of folate and the production of 5-methyltetrahydrofolate, which is used in the remethylation of homocysteine to methionine, an important step in the generation of methyl groups. Homozygosity for the MTHFR C677T variant is associated with a thermolabile form of the enzyme, ${ }^{7}$ elevated plasma total homocysteine levels, ${ }^{7,18}$ and global changes in DNA methylation. ${ }^{24-26}$ Given the metabolic tie of MTHFR to DNA methylation, an epigenetic process important for the regulation of gene expression, the mechanism by which the MTHFR 677T allele is associated with development of MetS in SGA-treated children may be related to changes in DNA methylation and a gene expression profile that favours development of MetS characteristics.

Prior studies in adult populations, with no underlying psychiatric diagnoses or SGA-treatment, have shown the MTHFR C677T variant is associated with an increased risk for cardiovascular disease, ${ }^{10}$ an effect attributed to elevations in plasma total homocysteine ${ }^{27}$ and the vascular metabolism of folates. ${ }^{28}$ In the current study, we were not able to quantify plasma total homocysteine levels. We also found significant associations of the T-allele of the MTHFR C677T variant with diastolic blood pressure Z-scores and fasting plasma glucose levels in SGA-treated children. Interestingly several studies in adult populations have reported associations of the MTHFR C677T variant with blood pressure. ${ }^{29-31} \mathrm{~A}$ meta-analysis showed that the MTHFR C677T variant is associated with increased risk for hypertension. ${ }^{29}$ Furthermore, recent genome-wide association studies have identified the MTHFR loci to be associated with systolic and diastolic blood pressure. $^{30,31}$ Therefore, the MTHFR C677T variant may have a strong influence on blood pressure in SGA-treated children and contribute to the association of the T-allele with MetS diagnosis.

Overall, this study is the first to demonstrate that the T-allele of the MTHFR C677T variant is associated with MetS and its characteristics of elevated blood pressure and higher fasting plasma glucose levels in SGA-treated children. The mechanism by which the MTHFR 677T allele may contribute to the development of MetS and its components is not known. Further studies are required to investigate potential mechanisms and to determine whether SGA-treatment produces disturbances in methyl metabolites and epigenetic changes in gene expression, especially those regulated by DNA methylation.

\section{Conflict of interest}

The authors declare no conflict of interest.

Acknowledgements. This work was funded by an establishment grant from the Child \& Family Research Institute and an operating grant from the Canadian Diabetes Association. C Panagiotopoulos is supported by Clinician Scientist Awards from the Child \& Family Research Institute and Canadian Diabetes Association. AM Devlin is supported by an Investigator Salary Award from the Child \& Family Research Institute.
1. Correll CU, Penzner JB, Parikh UH, Mughal T, Javed T, Carbon M et al. Recognizing and Monitoring Adverse Events of Second-Generation Antipsychotics in Children and Adolescents. Child Adolesc Psychiatr Clin N Am 2006; 15: 177-206.

2. Therapeutics Initiative. Increasing use of newer antipsychotics in children: $A$ cause for concern? 2009 April-June 2009.

3. Expert Panel on Detection Evaluation and Treatment of High Blood Cholesterol in Adults. Executive Summary of the Third Report of the National Cholesterol Education Program (NCEP) Expert Panel on Detection, Evaluation, and Treatment of High Blood Cholesterol in Adults (Adult Treatment Panel III). JAMA 2001; 285: 2486-2497.

4. The Expert Committee on the Diagnosis and Classification of Diabetes Mellitus ${ }^{*}$. Follow-up Report on the Diagnosis of Diabetes Mellitus. Diabetes Care 2003; 26: 3160-3167.

5. Panagiotopoulos C, Ronsley R, Kuzeljevic B, Davidson J. Waist circumference is a sensitive screening tool for assessment of metabolic syndrome risk in children treated with second-generation antipsychotics. Can J Psychiatry 2012; 57: 34-44.

6. Correll CU, Manu P, Olshanskiy V, Napolitano B, Kane JM, Malhotra AK. Cardiometabolic Risk of Second-Generation Antipsychotic Medications During First-Time Use in Children and Adolescents. JAMA 2009; 302: 1765-1773.

7. Frosst $P, B$ Bom HJ, Milos R, Goyette $P$, Sheppard CA, Matthews RG et al. A candidate genetic risk factor for vascular disease: a common mutation in methylenetetrahydrofolate reductase. Nat Genet 1995; 10: 111-113.

8. Peerbooms OLJ, van Os J, Drukker M, Kenis G, Hoogveld L, de Hert M, Delespaul P et al. Meta-analysis of MTHFR gene variants in schizophrenia, bipolar disorder and unipolar depressive disorder: Evidence for a common genetic vulnerability? Brain Behav and Immun 2011; 25: 1530-1543.

9. Joober R, Benkelfat C, Lal S, Bloom D, Labelle A, Lalonde P et al. Association between the methylenetetrahydrofolate reductase $677 \mathrm{C} \rightarrow$ T missense mutation and schizophrenia. Mol Psychiatry 2000; 5: 323-326.

10. Klerk M, Verhoef $\mathrm{P}$, Clarke R, Blom HJ, Kok FJ. MTHFR 677C-> T polymorphism and risk of coronary heart disease: a meta-analysis. JAMA 2002; 288: 2023-2031.

11. Ellingrod VL, Miller DD, Taylor SF, Moline J, Holman T, Kerr J. Metabolic syndrome and insulin resistance in schizophrenia patients receiving antipsychotics genotyped for the methylenetetrahydrofolate reductase (MTHFR) $677 \mathrm{C} / \mathrm{T}$ and 1298A/C variants. Schizophr Res 2008; 98: 47-54.

12. American Psychiatric Association. Diagnostic and Statistical Manual of Mental Disorders 4th edn. 2000 text revision. American Psychiatric Association. Washington DC, pp 32-35.

13. McCarthy HD, Jarrett KV, Crawley HF. The development of waist circumference percentiles in British children aged 5.0-16.9 y. Eur J Clin Nutr 2001; 55: 902-907.

14. Kuczmanski RJ, Ogden CL, Grummer-Strawn LM, Flegal KM, Guo SS, Wei R et al. CDC Growth Charts: United States. Advanced data from vital and health statistics; no. 314. Hyattsville, MD: National Center for Health Statistics, 2000.

15. Barlow SE. Expert Committee Recommendations Regarding the Prevention, Assessment, and Treatment of Child and Adolescent Overweight and Obesity: Summary Report. Pediatrics 2007; 120: S164-S192.

16. National High Blood Pressure Education Program Working Group on High Blood Pressure in Children and Adolescents. The Fourth Report on the Diagnosis, Evaluation, and Treatment of High Blood Pressure in Children and Adolescents. Pediatrics 2004; 114: 555-576.

17. Fernandez JR, Redden DT, Pietrobelli A, Allison DB. Waist circumference percentiles in nationally representative samples of African-American, European-American, and MexicanAmerican children and adolescents. J Pediatr 2004; 145: 439-444.

18. Devlin AM, Clarke R, Birks J, Evans JG, Halsted CH. Interactions among polymorphisms in folate-metabolizing genes and serum total homocysteine concentrations in a healthy elderly population. Am J Clin Nutr 2006; 83: 708-713.

19. Maayan LA, Vakhrusheva J. Risperidone associated weight, leptin, and anthropometric changes in children and adolescents with psychotic disorders in early treatment. Hum Psychopharmacol Clin Exp 2010; 25: 133-138.

20. Khan RA, Mican LM, Suehs BT. Effects of olanzapine and risperidone on metabolic factors in children and adolescents: a retrospective evaluation. J Psychiatr Pract 2009; 15: 320-328.

21. Devlin AM, Brain U, Austin J, Oberlander T. Prenatal Exposure to Maternal Depressed Mood and the MTHFR C677T Variant Affect SLC6A4 Methylation in Infants at Birth. PLoS ONE 2010; 5: e12201-e1220.

22. van Winkel R, Rutten BP, Peerbooms O, Peuskens J, van Os J, De Hert M. MTHFR and risk of metabolic syndrome in patients with schizophrenia. Schizophr Res 2010; 121: 193-198.

23. van Winkel R, Rutten BP, Peerbooms O, Peuskens J, van Os J, De Hert M. MTHFR genotype and differential evolution of metabolic parameters after initiation of a second generation antipsychotic: an observational study. Int Clin Psychopharmacol 2010; 25: 270-276.

24. Castro R, Rivera I, Ravasco P, Camilo ME, Jakobs C, Blom HJ et al. 5,10methylenetetrahydrofolate reductase (MTHFR) $677 \mathrm{C}->\mathrm{T}$ and $1298 \mathrm{~A}->\mathrm{C}$ mutations are associated with DNA hypomethylation. J Med Genet 2004; 41: 454-458.

25. Sohn KJ, Jang H, Campan M, Weisenberger DJ, Dickhout J, Wang YC et al. The methylenetetrahydrofolate reductase C677T mutation induces cell-specific changes in genomic DNA methylation and uracil misincorporation: a possible molecular basis for the site-specific cancer risk modification. Int J Cancer 2009; 124: 1999-2005.

26. Friso S, Choi SW, Girelli D, Mason JB, Dolnikowski GG, Bagley PJ et al. A common mutation in the 5,10-methylenetetrahydrofolate reductase gene affects genomic DNA methylation through an interaction with folate status. Proc Natl Acad Sci USA 2002; 99: 5606-5611. 
27. Homocysteine Studies Collaboration. Homocysteine and risk of ischemic heart disease and stroke: a meta-analysis. JAMA 2002; 288: 2015-2022.

28. Antoniades $\mathrm{C}$, Shirodaria $\mathrm{C}$, Leeson $\mathrm{P}$, Baarholm OA, Van-Assche $\mathrm{T}$, Cunnington $\mathrm{C}$ et al. MTHFR 677 C > T Polymorphism Reveals Functional Importance for 5-Methyltetrahydrofolate, Not Homocysteine, in Regulation of Vascular Redox State and Endothelial Function in Human Atherosclerosis. Circulation 2009; 119: 2507-2515.

29. Qian X, Lu Z, Tan M, Liu H, Lu D. A meta-analysis of association between C677T polymorphism in the methylenetetrahydrofolate reductase gene and hypertension. Eur $J$ Hum Genet 2007; 15: 1239-1245.

30. Newton-Cheh C, Johnson T, Gateva V, Tobin MD, Bochud M, Coin L et al. Genome-wide association study identifies eight loci associated with blood pressure. Nat Genet 2009; 41 666-676.
31. Takeuchi F, Isono M, Katsuya T, Yamamoto K, Yokota M, Sugiyama T et al. Blood Pressure and Hypertension Are Associated With 7 Loci in the Japanese Population. Circulation 2010; 121: 2302-2309.

Translational Psychiatry is an open-access journal published by Nature Publishing Group. This work is licensed under the Creative Commons Attribution-NoncommercialNo Derivative Works 3.0 Unported License. To view a copy of this license, visit http://creativecommons.org/licenses/by-nc-nd/3.0/ 